\title{
Editorial
}

\section{Microfluidics in system biology}

The idea of devoting a Special Issue of ELECTROPHORESIS to biological applications of microfluidics, with the emphasis on the analysis of complex biological systems (understood as the analysis of living beings at different levels of organisation, be it DNA, RNA, proteins or metabolites, and their interactions) was initiated at the HPCE 2004 meeting in Salzburg, Austria. During discussions with Prof. Radola, it became clear that microfluidics was maturing from a purely technology-driven field into a toolbox that may prove useful in addressing the analytical requirements of genomics, proteomics and metabolomics [1]. The transition from proof-of-principle prototypes to routine, commercially available analytical tools has to be put in perspective with the relatively recent entry of industrial players into the field who bring concepts to the market and end-users.

The ambitious and incentive goal of this Special Issue was to accompany this transition from technology-oriented microfluidic developments (which is still a booming field) to their use in the biological exploration of complex systems, and to provide a platform to discuss the potential of this new generation of analytical devices for tackling the analytical demands of integrative biology. The works presented in this Issue provide a good picture of the field: a lot of efforts are devoted to technological developments, such as the integration of or hyphenation with new detectors (among which mass spectrometry is receiving more and more attention), integration of microfluidics into whole analytical processes, and the development of entirely new electrokinetic or separation processes based on the intrinsic properties of microfluidics. The last section of this Issue is devoted to the application of microfluidics in various biological domains. We hope that this Special Issue will help to crystallise the transition toward more biologically oriented projects in microfluidics, a field that no doubt will grow in the near future.

We wish to thank all authors for their contributions, all reviewers who have committed themselves to help us prepare this Issue, and Prof. El Rassi for his invaluable help in the editing process.

We would also like to express our gratitude to Prof. Radola for initiating this Special Issue and for his continuous encouragement. We wish him a happy and healthy retirement.

Niels Lion

Joël S. Rossier

Hubert H. Girault

[1] Foret, F., Electrophoresis 2004, 25, 3477. 